This is the peer reviewed version of the following article: Gallagher, Ann, Curtis, Katherine, Dunn, Michael and Baillie, Lesley (2017) Realising dignity in care home practice : an action research project. International Journal of Older People Nursing, 12(2), e12128., which has been published in final form at https://doi.org/10.1111/ opn.12128. This article may be used for non-commercial purposes in accordance with Wiley Terms and Conditions for Use of Self-Archived Versions 


\title{
Realising Dignity in Care Home Practice: An Action Research Project
}

\author{
Gallagher, A.; Curtis, K.; Dunn, M.; and Baillie, L.
}

\begin{abstract}
Background: More than 400,000 older people reside in over 18,000 care homes in England. A recent social care survey found up to $50 \%$ of older people in care homes felt their dignity was undermined. Upholding the dignity of older people in care homes has implications for residents' experiences and the role of registered nurses.
\end{abstract}

Aims and Objectives: The study aimed to explore how best to translate the concept of dignity into care home practice, and how to support this translation process by enabling registered nurses to provide ethical leadership within the care home setting.

Design: Action Research with groups of staff (registered nurses and non-registered care-givers) and groups of residents and relatives in 4 care homes in the south of England to contribute to the dignity toolkit development.

Methods: Action research groups were facilitated by 2 researchers to discuss dignity principles and experiences within care homes. These groups reviewed and developed a dignity toolkit over 6 cycles of activity (once a month for 6 months). The registered nurses were individually interviewed before and after the activity.

Results: Hard copy and online versions of a dignity toolkit, with tailored versions for participating care homes, were developed. Registered nurses and care-givers identified positive impact of making time for discussion about dignity-related issues. Registered nurses identified on-going opportunities for using their toolkit to support all staff.

Conclusions: Nurses and care-givers expressed feelings of empowerment by the process of Action Research. The collaborative development of a dignity toolkit within each care home has the potential to enable ethical leadership by registered nurses that would support and sustain dignity in care homes.

Implications for Practice: Action Research methods empower staff to maintain dignity for older people within the care home setting through the development of practically useful toolkits to support everyday care practice. Providing opportunities for care-givers to be involved in such initiatives may promote their dignity and sense of being valued. The potential of bottom-up collaborative approaches to promote dignity in care therefore requires further research.

Key words. Dignity, Care homes, Action Research, Older people, Toolkit, Ethics 
What does this research add to existing knowledge in gerontology?

- The development of dignity toolkits through a process that enables time and space for dignity-related discussion among staff, residents and relatives provides opportunity for improvements in dignified care provision in residential settings.

- Providing registered nurses with the tools to take a leading role in developing dignity in care contributes to their empowerment and to the realisation of ethical care in practice.

What are the implications of this new knowledge for nursing care with older people?

- The study suggests the importance of providing opportunities for all staff within care homes to engage in research with a view to maintaining and improving nursing care and leadership of care.

- Enabling collaborative research that encourages discussion between and within staff and resident/relative groups can maximise a sense of dignity among all participants that promotes an environment for dignifying care.

How could the findings be used to influence policy or practice or research or education?

- Findings suggest the value of care home managers recognising the importance of making time and space for dignity-related discussions within residential care settings.

- The collaborative development of toolkits with the potential to promote ethical practice requires further exploration, particularly regarding collaborators' sense of being valued for their participation and the potential for empowerment to change practice. 


\section{Introduction}

The concept of dignity has received a good deal of attention from practitioners, researchers, philosophers and theologians in recent years (Naden et al 2013, Chochinov 2012, Matiti and Baillie 2011, Kateb 2011). Much international attention has focused on dignity within the care of older people specifically (Franklin et al 2006, Gallagher et al 2008, Nordenfelt 2009, Naden et al 2013, Tranvåg et al 2015, Lohne et al 2016), particularly in light of concerns raised about the quality of care provided. The Delivering Dignity report estimated that $17 \%$ per cent of the UK population were aged 65 and over (10.3 million people), with 1.4 million of them aged 85 and over and that in England, more than 400,000 people aged over 65 are living in over 18,000 care homes (Commission on Dignity in Care, 2012). This report also emphasised the important role of care homes in taking responsibility for safeguarding vulnerable older adults and providing dignified care. Despite this, a recent survey by Ross (2013) found that up to $50 \%$ of older people in care homes feared abuse and many felt their dignity was undermined. In Defence of Dignity from The Northern Ireland Human Rights Commission (2012) provided further detail on specific areas that render older people in care homes vulnerable to indignity; specifically in relation to their personal care, eating and drinking, medication and restraint.

There are many definitions and philosophical frameworks relating to dignity (Gallagher 2004; Nordenfelt 2009), and disagreement remains about the value of the concept (Mackin 2003; Pinker 2008). Notwithstanding these uncertainties, dignity as a concept for improving the quality of care has gained significant traction in England and international policy contexts. Perhaps most helpfully for our purposes here, given the UK policy context in which we are based, the Royal College of Nursing (RCN) Defending Dignity in Care report (Baillie, Gallagher \& Wainwright 2008 p.8) states that:

Dignity is concerned with how people feel, think and behave in relation to the worth or value of themselves and others. To treat someone with dignity is to treat them as being of worth, in a way that is respectful of them as valued individuals.

The RCN definition of dignity continues:

Dignity applies equally to those who have capacity and to those who lack it. Everyone has equal worth as human beings and must be treated as if they are able to feel, think and behave in relation to their own worth or value.

The nursing team should, therefore, treat all people in all settings and of any health status with dignity, and dignified care should continue after death.

The Nursing and Midwifery Council (NMC) responsible for the regulation of the UK nursing profession requires nurses to 'treat people as individuals and uphold their dignity' (NMC 2015). A report commissioned by the Royal College of Nursing found that dignity within care settings may be promoted or diminished by: the physical environment; organisational culture; the attitudes and behaviour of nurses and others; and in the way care activities are carried out (Baillie, Gallagher \& Wainwright 2008 p.8). This focus on dignity as a core component to the quality of nursing care is 
mirrored in other countries. In Canada (through the Canadian Nurses Association's Code of Ethics), South Australia (through a 2011 governmental initiative), Ireland (through the Nursing Midwifery Board), similar policy drives to ensure that care is provided in a dignified manner have been undertaken. In these countries, principles and toolkits have also been adopted, and so it is likely that similar concerns arise about how dignity should be translated into practice using practically-relevant and tailored activities.

Alongside these policy developments, qualitative research on dignity in care homes highlighted the importance of care home residents needing to be seen, respected and having their identity maintained (Franklin et al 2006). Findings from a UK qualitative study by Hall et al (2014) reported themes of independence, privacy, comfort and care, communication and 'being seen as human' (Hall 2014).

Whilst dignity has gained traction as a concept through which professionals can improve the quality of the care they provide to patients and other service users, there is a dearth of academic study or other forms of evidence on how best to translate the concept of dignity into practical implications for care delivery. In this sense, 'dignity' as a concept is short of 'real-world' detail. As a report from the Picker Institute states 'It is easier to make pronouncements about dignity than to ensure that dignified care happens' (Magee et al 2009 p.9). It is then uncertain precisely how care practices that are dignifying can be established, fostered, and disseminated within care settings.

Professional bodies in the UK have sought to close this gap between concept and practice, with the RCN introducing a 'dignity toolkit' and Skills for Care launching a 'dignity guide', both of which are built around core principles and case studies. Whilst there is some evidence that ethics-related toolkits have potential to impact positively on care practice (see Ramage et al 2015), it is not precisely clear how practitioners ought to instigate such toolkits, and how the relevant case studies (and other aspects of the training materials such as presentations and animations), can be best used to reform the delivery of everyday care in ways that respect dignity to the greatest extent possible in specific care environments.

One identified concern in translating dignity into practice is the question of leadership and responsibility: who precisely ought to marshal the process of enacting dignity into the everyday spaces of care practice? In response to the Francis reports that identified leadership failings in care in England, the King's Fund (2013) leadership survey found that 'leadership development should give priority to supporting leaders at all levels to be patient-centred [...]'. While some Registered Nurses (RNs) have formal leadership roles, all RNs in England are now expected to take responsibility for influencing dignity in care and as such might be understood to be 'ethical leaders'. Whether or not RNs have formal leadership responsibilities, ethical leadership can be understood to have a number of facets and incorporate different leadership styles (Bjarnson \& LaSala 2011). Gallagher and Tschudin (2010) suggest that ethical leadership aspires to promotion of good ends at the same time as paying attention to how those ends are reached. Ethical leadership is also concerned with influencing others to behave ethically, for example, through role modelling (Sama \& Shoaf 2007). It is important to acknowledge, therefore, that the successful translation of dignity into care practice will require some form of ethical leadership in a care 
setting, and that RNs working in England are formally expected to engage in such leadership as part of their roles.

In light of this backdrop, the ENACT project was developed in order to address two key aims associated with promoting dignity in care practice: 1) to ascertain how dignity, as a key concept identified by service users, practitioners and policy makers to underpin good care, should be enacted in specific care home environments; and 2) to establish how RNs could utilise a dignity toolkit and reflective process to support ethical leadership to translate dignity into care home practice. Given the lack of evidence about which strategies could be best used to meet these aims, and very limited understanding of the role that dignity plays in care home practice more generally, it was judged that a research approach that connected real-world changes with the ongoing evaluation of these changes, would be most appropriate. Thus, the ENACT project adopted an action research methodology to develop a dignity toolkit centred on specific care interventions that were tailored to the context of individual care homes, introduced and disseminated by RNs, and refined and evaluated over the course of the project. Toolkits (or tool kits) are often used in education and can comprise different tools, take various forms (for example, hard copy or online) and are created for a specific purpose. They have also been developed as a resource for students in ethics education (see, for example, British Medical Association 2016) and also to stimulate reflection in relation to concepts such as compassion in care (Curtis 2016).

This paper reports details of the toolkit development and project evaluation findings from the action research activities and additional qualitative interviews with registered nurses.

The theoretical framework underpinning this project has three components: the recognised contribution of action research to practice development (Dewar and Sharp 2013); dignity scholarship and research (Gallagher 2011); and pedagogic insights regarding ethics education and reflective practice (Hart and Cooper 2015).

\section{Method}

Action research is research 'with' participants rather than 'on' them (Williamson, Bellman \& Webster 2012) so that changes in practice can be achieved (McLeod 2011). The participants or action researchers in this project are the residential care home staff (RNs and care workers), with contributions from resident and relative participants, and action research support and facilitation from pairs of academic researchers. We appreciate that there is value in conducting an in-depth analysis of the experiences and perspectives of residents and relatives who participated in the RRG's and this is recommended in future, however, the focus of this paper is on the experiences of registered nurses. The action research process is cyclical and consists of planning, action, monitoring and reflection, with on-going evaluation; bringing together action and reflection to find solutions to practical concerns while enabling the flourishing of participants in the process (Williamson, Bellman \& Webster 2012).

In this action research design, the participatory approach was adopted in order to ensure that practice development took place in ways that were closely aligned to policy priorities. As such, the goals of the action research process were focused 
firmly on the challenge of ensuring that the concept of dignity was useful and fit for purpose for residential care, with additional methods adopted to examine how nurses could develop their role as ethical leaders around the concept of dignity in the care home environment. With the project having been undertaken prior to the release of the RCN's and Skills for Care's toolkits, the project team and an Advisory Group of experts in the field of care developed a selection of suggested activities based upon the Skills for Care seven 'common core principles' relating to dignity (Skills for Care 2012). It was necessary to adopt this approach in order to instigate the action research activities in care homes in ways that were comparable and congruent with care policy. These common core principles were stated in the initial version of the Dignity Toolkit and reduced as the iterative action research process progressed. Within this standardised approach adopted by the project team, the goals of the participants themselves drove the development of the action research activities and the refinement of the dignity toolkit and its instigation into practice in the different care home settings.

As introduced above, the project was supported by an expert Advisory Group. The Advisory Group brought different areas of expertise to the project. Primarily the Advisory Group worked with the Research Team to develop and refine the Toolkit. The process was iterative and the Toolkit activities tried out with the Action Research Groups in the care homes and feedback then brought back to the Advisory Group and the Toolkit refined further.

\section{Setting}

The ENACT project recruited volunteers from 4 care homes located in the South of England. The four care homes were approached following recommendations from members of the Advisory Group. Initial contact was made following a favourable ethical opinion of the project from the University Research Ethics Committee and site participation was achieved through direct requests to the care home managers. The 4 care homes that took part varied in terms of size and organisation; one being an independent care home specialising in mental health and dementia care, and three belonging to large national care home companies. Bed numbers in each home varied from 46 to 97 .

\section{Sampling and Recruitment}

Project researchers recruited volunteer RNs and care workers to an Action Research Group (ARG) within each home, and recruited volunteer residents and relatives to a Residents \& Relatives Group (RRG) in each home in order that they could contribute to the toolkit development activities within their home. Potential participants of the ARGs and RRGs were provided with participant information sheets and invited to participate, with time to consider the information and ask questions. All participants provided fully informed consent and principles of ethical research were upheld such as respect for anonymity and confidentiality. Recruitment to the 4 ARGs ranged from 6 to 9 participants, including 1 or 2 RNs in each ARG, with an average of 7 people in attendance at each of the 6 ARG meetings held in each home.

Recruitment to the 4 RRGs ranged from 1 to 5 residents plus 1 to 4 relatives in each $R R G$, with an average of 4 people in attendance at each of the 6 RRG meetings. Dates for the 6 meetings were identified with the ARGs and RRGs at the start of the project to maximise attendance and each $A R G$ and $R R G$ meeting lasted 
approximately one hour with refreshments provided. Two academic researchers were present to facilitate and support the ARG and RRG activity at each of the monthly meetings.

\section{Data collection}

The project engaged with the RNs in particular, encouraging them to be leaders of their ARG with the care-worker participants who were employed in the same care home. Qualitative data were collected through digital recordings of ARG and RRG discussions at each home and each meeting, and through notes taken by pairs of academic researchers who facilitated the meetings. Further data were collected though individual interviews with $2 \mathrm{RNs}$ at each home $(n=8)$, once at the start of the project and once at the end. These interviews were designed to support the action research process by identifying specific opportunities for RNs to take the lead in supporting dignity in care, and issues in them adopting such a role in the individual care homes. Data were also collected through final reflections of the academic researchers who facilitated the ARGs and RRGs. These reflections were intended to capture additional insights into the action research process, particularly concerning those aspects of the process that had enabled dignity in care to be translated into practice in optimal or sub-optimal ways. Following an initial RN interview where their views on dignity, their role in promoting dignified care and their confidence in working with colleagues to promote dignity were discussed, the final RN interview enabled exploration of the process of leading the ARG and development of their dignity toolkit. Figure 1 illustrates the action research process.

Within an action research design, data can be collected and analysed using a range of methods. Interview data were analysed using Braun and Clarke's (2006) approach to thematic analysis as this was appropriate for these data. This is a six-phase process as follows:

1. Familiarising yourself with the data

2. Generating initial codes

3. Searching for themes

4. Reviewing themes

5. Defining and naming themes

6. Producing the report

\section{Results}

Findings from the ENACT project evaluation are divided into: the development of the dignity toolkit through action research; and the themes arising from $\mathrm{RN}$ interviews.

\section{The Development of the ENACT project Dignity Toolkit}

As action research is participatory and the RNs were facilitated to lead the activity, the development and refinement of the toolkit was the focus for the majority of the project. The Action Research process involved monthly meetings with ARGs and RRGs to discuss topics from the baseline version of the toolkit. This 'baseline toolkit' took the form of a series of introductory activities designed by the research team and advisory group, and based on Skills for Care's seven 'common core principles'. 
Details of the activities that comprised the action research process to develop the toolkit in each of the six sessions are described below.

The 7 sections of the toolkit were amended, added to and refined as the action research process progressed across 6 repeating cycles of implementation of activities, evaluation and redevelopment took place with members of each ARG in the 4 homes. The RRGs discussed the suggested activities and toolkit information as it was refined, and contributed specific activities to the 5 sections within the revised toolkit. The Action Research process within the care homes comprised 6 sessions as follows, each focusing on one or more of the Skills for Care seven principles, but with differences across the four homes dependent on the specific objectives and foci expressed by members of the groups within these homes. The differences in focus across the four homes were all captured within the revisions made to the toolkit.

Session 1 - The focus of this session was on 'understanding dignity' and on participants' views of the meaning of dignity and views of what increases and challenges dignity in care. Regarding 'what dignity means?' members of the ARGs identified: respect, seeing each other as an individual, taking the person as a whole, being discreet, treating as I would like to be treated, setting people up for success, not using patronising language, using your body language to show you care e.g. use of touch and smiling. Members of the RRGs referred to giving time, getting to know the individual, showing human warmth, consider as a family, having fun and a joke and being aware of responses e.g. asking 'what can I do for you?' rather than 'what do you want' and acknowledging residents:

We'll walk down the corridor, it doesn't matter if you see them 65 times that morning, you know, you say 'hello', you acknowledge them as a person, you know they might choose to walk past you, they might choose to talk to you, and it's little things like letting them come along with you to make a bed, or just follow you and be with you. But you don't ignore them as a person, acknowledge them.

Session 2-This second session focused on participants' experience and views of 'the potential of a dignity toolkit'. There was a view that a toolkit should be 'direct and simple' and that it should include examples and exercises. Following the session 1 discussion and consultation with the Advisory Group, it was proposed that the 7 principles of dignity from the Skills for Care dignity resource principles that were included in the initial version of the Dignity Toolkit, should be reduced to 4 . These are:

i) support and care for me in ways that value who I am

ii) communicate with me so that I am understood and my needs are met

iii) work together to provide care that is safe and respectful of my feelings and to create an environment where I can feel at home

iv) be prepared to speak up on my behalf and on behalf of others, in order to protect and promote everybody's dignity.

Session 3 - This third session focused on 'communication and dignity' and participants in the ARGs had the opportunity to try out and give feedback on the 4 exercises in section 3 of the draft toolkit. These were viewed positively although there were different opinions about 'role play' exercises with some saying this could 
be very effective and others saying they did not like role play. The discussion at the RRGs highlighted the importance of an empathic approach, politeness and of nonverbal communication such as smiling. Members of both the ARGs and the RRGs were invited to share 'top tips for communicating dignity'. Some of these are published in Section 3 of the toolkit and include: refer to resident and relative by preferred name; speak to people with 'one voice' not many people giving instructions; give people time to respond; and give the person your whole, undivided attention when you are talking with them. Here, paying and giving attention to residents and their families was seen as important to dignifying care:

It doesn't matter how far you think the dementia's gone if you actually take the time to get to know somebody. Even if they can't verbally communicate with words, they could just communicate with voices, you can see that they understand because they respond to your voice if you take the time and trouble to know them. And you can see in their eyes when you get to know your resident the different responses and the changes to different things, different stimuli, different questions and things like that

Session 4 - This session focused on 'dignity conversations' and their role in supporting dignity in care. A potential dignity promotion strategy suggested in team and Advisory Group discussions focused on the value of staff members having time and space for conversations around dignity (section 4 of the toolkit). A specific framework for conversations of this type was developed and applied to examples shared by ARG and RRG members. One topic area related to truth-telling. ARG members shared dilemmas relating to truth-telling and dementia care, for example, what should you do when a person experiencing dementia repeatedly asks for her husband who staff know is deceased? In one of the RRGs a relative shared an example of withholding information from a resident who had severe dementia. He had not told his wife of the wedding of their daughter because, he said, she would say 'can I come?' Such examples were used for reflective discussions.

Session 5 - The penultimate ARG and RRG focused on 'ethical leadership'. This section of the toolkit had not been developed prior to the action research process commencing, and was drafted de novo after session 5. Group members shared many examples of individual, organisational and external factors that impacted on dignity in care: the importance of role modelling and leading by example; the provision of training and induction; supporting staff and attending to their welfare; and organisational culture that acknowledged dignifying care saying 'well done'. A relative talked of the importance of leaders making the 'atmosphere light and pleasant' and of being 'gentle'.

Session 6 - The final session comprised a summary of previous sessions and an invitation to evaluate the toolkit and the overall action research process. The discussion was generally positive with comments on the value of specific elements of the toolkit, for example. "I like the family bit and "what can I do for you?"' section. When asked about the development of the toolkit there were some different views about how the information in the toolkit ought to be disseminated, with some ARGs favouring a 'durable pocket guide' and others posters ('you can look at it while you are having a cup of tea'). 
After the final $A R G$ and $R R G$ meetings, the academic researchers transferred the dignity toolkit into the ARG's/RRG's requested format/s (online version, dignity pocket guide and/or poster) specific to each care home, and then provided each care home manager with these versions of their dignity toolkit in a final meeting to thank them for their participation. Any on-going development and utilisation of the dignity toolkit was handed over to each care home with an understanding that it was to be led by RNs and involve contributions from care workers, residents and relatives.

The 'tailoring' of the Toolkit for each home also included adding ARG and RRG responses on their understanding of dignity and dignified care, and included their '10 Top Tips' for communication that promotes dignity within their care home.

The ARGs identified their preferred format for their dignity toolkit and this ranged from a laminated pocket guide to a workbook and poster. All 4 care homes were given access to an online version of their toolkit so that they could own and manage any further developments (See http://dignitytoolkitsurrey.org/abouttheproject.html ).

\section{Qualitative Data from RN Interviews}

Transcriptions of audio data from the individual interviews with RNs at the beginning and end of the project were also analysed for common themes, and two such themes emerged: i) Leading dignified care; and ii) Ethical leadership and empowerment.

Leading dignified care describes participants' views on and experiences of leading dignified care. It includes the sub-themes: the leadership role and the practice of leadership. In talking about their leadership role, the RNs acknowledged the responsibility that goes with having a leadership role within their care homes:

[When] I'm in charge of the shift, and if someone phones up sick I need to find staff. I mean there is pressure to be in charge of a shift.

They also described the extent to which they had confidence in their own and others' leadership, with confidence coming from experience and lack of confidence coming from perceived lack of experience:

I think [I'm] very confident. I'm older than obviously a lot, I tend to be the old school nursing - we were talking about that this morning ... you are peopleorientated from the word go.

Trust, and sometimes lack of trust in their staff was also referred to:

I have a fairly small team, but we're all working towards a common goal ...

We're lucky to have found them ... I rely on them very much.

Finally, having a leadership role was understood in the context of being part of the team, so that while the responsibility of the leadership role was seen as sometimes separating them from other team members, the importance of being prepared to work alongside care staff was also emphasised. 
'Ethical leadership and empowerment' was a recognised outcome from engagement in the ENACT project. RNs were asked about their experiences of developing a Dignity Toolkit through the Action Research process. One of the positive experiences reported was the opportunity to share experiences. This had led to a broadening and deepening of their understanding of dignity:

...it's all been beneficial because it's good to hear specially within the group discussions other people's thoughts and ideas, which they maybe wouldn't express on the unit or in unit meeting.

At the same time, this opportunity had been experienced as valuable in itself, with RNs appreciating the chance for themselves and their colleagues to be heard and to have their views taken seriously:

For me the positive thing was we could say what we want to say and [the researchers] ... didn't tell us [their] point of view ... we could be really honest without judgement.

RNs were also asked about their understanding of ethical leadership, and their own role as an ethical leader. For some participants, ethical leadership was understood in terms of ethical decision making:

It's about managing things like the mental capacity of people to make sure that you're making those decisions correctly and supporting people in those decisions and that you're doing things for the right reasons.

Overall, the participants felt that they were empowered, by virtue of their position and responsibilities, and the support and expectations of their managers. One participant reflected on the relationship between care for the individual resident and the wider context in which that care is provided:

No it was really nice actually, really really nice, this project. And hopefully I think we will see and act with this, because it's so important. I'm terrified sometimes when I see - I don't want to see more problems [on] TV and all of that about nursing homes ... because l've got this kind of passion for elderly (people), and I just want all of them to be happy [...] And if I could change, even if it was a little bit, change [someone's] life and make them feel useful because they are useful, it will make all the difference for me at least and ... even if it's just for one person if I can change the way people, society look to persons in nursing homes, I would be really really happy. And I will use all the resources I've got and this [toolkit], everything what I can use to change that, I will do it for sure.

\section{Discussion}

The project data suggest that the outcomes of the ENACT project were realised through the design of dignity toolkits specific to the 4 care homes participating in the project. Alongside this, the qualitative data concerning the research team's personal reflections provided some insight into the value of dignity-promoting initiatives within residential care settings for older people; namely: 
- the positive impact of making time and space in care homes for discussion about dignity-related issues for staff, as this is valued highly by staff, residents and relatives,

- that the project process is as important as project outputs, as Action Research enables staff to be listened to and to have one's views considered important was highly valued by participants, and

- the value and potential of using bottom-up collaborative approaches to promote dignity in care homes.

The overall ENACT project evaluation and feedback from the action research group participants suggest that an outcome of engagement in action research was a sense of being valued, and of having dignity enhanced through involvement. Although empowerment of participants through action research is not a new phenomenon (Jones \& Gelling 2013), this project has shown explicitly that having a voice and being listened to may contribute to improving the day-to-day delivery of dignified care. For the RNs specifically, this sense of being valued and empowered emphasised their responsibility as leaders of ethical care; an aspiration to promote good quality care (Gallagher and Tschudin 2010) and added to the effectiveness of their leadership through enabling them to role model dignity in care during the action research cycles (Sama \& Shoaf 2007). Project findings suggest the notion that empowerment exerts a positive influence in terms of self-identity, sense of purpose, supportive relationships, finding a voice, and social and self-awareness (Coser et al., 2014). Creating a 'partnership' between carers and care recipients is recognised as empowering and beneficial (Latimer, 2014), particularly with disempowered groups such as older people and care home residents. Providing opportunity for older people living in care homes and all those staff that provide care for them to contribute to ethical approaches in care and changes to improve ethical practice requires further consideration in terms of residential care environments. Attention to the dignity of staff in care homes is also worthy of future research attention building on work conducted in the acute sector (Khademi 2012, Sabatino et al 2012, Sturm \& Dellert 2015).

Alongside the improved sense of empowerment for instigating change in practice, the RNs involved in the ENACT project developed their understanding of their role in ethical leadership within the care home. The ENACT RNs expressed a sense of achievement from being involved in developing and evaluating the toolkit and its activities with their care workers. Although they had not described their involvement as 'ethical leadership', they were able to articulate that as RNs they had a responsibility to role model 'doing the right thing' in terms of promoting dignity and supporting care workers in providing dignified care to residents. Although some RNs expressed uncertainty in defining 'ethical leadership', a concept that exists at different levels and is recognised as complex (Gallagher \& Tschudin 2010), they could clearly identify their responsibilities for leading teams of care workers in ways that promoted respectful and compassionate care.

Perhaps most importantly, the ENACT project supported the development of a tailored resource to instigate dignified care in residential care homes in ways that are appropriate for this care setting. Adopting an approach that is tailored to the concerns and issues arising around care quality in residential care homes increases the likelihood of the dignity toolkit being taken up within these settings. 


\section{Implications for Practice}

This project has highlighted the value of making time and space in care homes for dignity discussions between staff and between staff and the residents and/or their relatives. Providing opportunities for discussion of complex concepts such as dignity not only empowers those taking part and adds to their sense of self-worth, it also enables collaboration that in turn can effect change for the better.

A collaborative, action research approach empowers registered nurses to lead on care improvements, and specifically dignity, for older people within care home settings. Action research leads to active engagement of staff, residents and families, enables their voices to be heard and promotes bottom-up changes to improve care. The collaborative development of interventions to improve care, such as the dignity toolkit in this project, appears to promote satisfaction and dignity and a sense of being valued for those involved. The dignity toolkit that was developed collaboratively within this project is freely available (http://dignitytoolkitsurrey.org/index.html) and could be used by other care homes.

This study has outlined a process, and delivered outcomes, that could improve dignity in residential care across England, and potentially in similar care settings in other countries. The level of enthusiasm amongst participants for the project was notable and should not be underestimated. However, the implications for practice need to be offset by the fact that we do not know whether the insights gained in the project will endure over the longer term, and it is also important to note that the study took place in only a limited number of care homes within one geographical area. Ongoing utilisation of the toolkit was not evaluated during the subsequent months following completion of the ENACT project, and so its sustainability was not tested. One value of the approach adopted is its scalability, with care homes being able to instigate a process similar to this one in ways that parallel standard team meetings and training development activities. Yet, further research to explore the value of toolkits developed by staff for their work would help to enhance understanding of the best means to enact change for improved ethical practice.

Overall, this project suggests there is real importance to care home management, and the RNs leading the delivery of care, to make time and space to listen to staff and to the residents and their relatives. We have shown that collaborative working is important in realising practically relevant changes to dignity in care - a priority for care settings across the world, not those just based in England. On this point, our work concurs with claims made elsewhere that if change is seen as a collaborative venture with alignment between needs and developments, then the benefits are visible to all involved in determining that change and the change is much more likely to be adopted and sustained (Grant et al. 2010). Using a 'bottom up' approach to improve ethical practice within care homes provides opportunity for improvements in dignified care provision in residential settings.

No conflict of interest has been declared by the authors. 


\section{References}

Baillie L, Gallagher A, Wainwright P (2008). Defending dignity in care: challenges and opportunities for nurses. London: Royal College of Nursing.

BBC News 'Care home abuse: Staff sacked or suspended over poor care' $30^{\text {th }}$ April 2014a (see http://www.bbc.co.uk/news/uk-27217218)

BBC News "Orchid View care home scandal review 'not enough"' 9 $^{\text {th }}$ June 2014b (see http://www.bbc.co.uk/news/uk-england-sussex-27761939).

Bjarnson D \& LaSala C A, (2011). Moral leadership in nursing. Journal of Radiology Nursing; 30, 18-24

Braun V, \& Clark V. (2006). Using thematic analysis in psychology. Qualitative Research in Psychology; 3 (2), 77-101

British Medical Association (2016) Medical students tool kit introduction (see https://www.bma.org.uk/advice/employment/ethics/medical-students-ethicstoolkit/introduction - accessed 21st June 2016)

Burdett Trust for Nursing (2013) Grant Programme: Delivering dignity through empowered leadership (see http://www.btfn.org.uk/grant-programmes/ )

Chochinov H.M. (2012) Dignity Therapy: Final Words for Final Days Oxford University Press, Oxford

Commission on Dignity in Care (2012). Delivering Dignity: Securing dignity in care for older people in hospitals and care homes. Accessed online:

http://www.nhsconfed.org/Publications/Documents/Delivering_Dignity_final_report15 0612.pdf (accessed 05/07/15)

Coser L., Tozer K., Van Borek N., Tzemis D., Taylor D., Saewyc E \& Buxton J. (2014) Finding a Voice: Participatory research with street-involved youth in the Youth Injection Prevention Project. Health Promotion Practice, 15(5), 732-738.

Curtis K. Gallagher A., Ramage C., Montgomery J., Leng J., Martin., C., Theodosius C., Anderson J., Glynn A., \& Wrigley M. (2016) Using Appreciative Enquiry to develop, implement and evaluate a multi-organisation 'Cultivating Compassion' programme for health professional and support staff' - currently being revised for special issue of Journal of Research in Nursing

- Dewar B. \& Sharp C. (2013) Appreciative dialogue for co-facilitation in action research and practice development: Critical Reflection on Practice Development 
International Practice Development Journal 3 (2), Article 7 (see

http://www.fons.org/library/journal/volume3-issue2/article7)

Dwyer L-L., Andershed B., Nordenfelt L. \& Temestedt B-M. (2009) Dignity as experienced by nursing home staff International Journal of Older People Nursing Vol 4., Issue 3, pp.185-193

Franklin L-L., Ternestedt B-M. \& Nordenfelt L.(2006). Views on dignity of elderly nursing home residents. Nursing Ethics; 13(2), 130-14

Gallagher A. (2004). Dignity and Respect for Dignity - Two Key Health Professional Values: Implications for Everyday Nursing Practice' in Nursing Ethics 11 (6), 587-599

Gallagher A, Li S, Wainwright P, Rees Jones I, Lee D (2008). Dignity in the care of older people: a review of the theoretical and empirical literature. BMC Nursing; $7(1)$,

Gallagher A \& Tschudin V. (2010). Educating for ethical leadership. Nurse Education Today; 30(3), 224-7

Gallagher A. (2011). Editorial: What do we know about dignity in care? Nursing Ethics; 18(4), 471-473

Gallagher A. \& Cox A. (2015) The RIPE Project protocol: Researching Interventions that Promote Ethics in Social Care Working Papers in Health Sciences (http://www.southampton.ac.uk/assets/centresresearch/documents/wphs/AGRIPE.pd f)

Grant B., Colello S., Riehle M. \& Dende D. (2010) An evaluation of the nursing practice environment and successful change management using the new generation Magnet Model. Journal of Nursing Management, 18, 326-331

Hall S., Dodd R, Higginson I. \& Irene J. (2014) Maintaining dignity for residents of care homes: A qualitative study of views of care home staff, community nurses, residents and families Geriatric Nursing Vol. 35, No.1, p. 55-60

Hart P. \& Cooper N. (2015)

'Reflective practice undertaken by healthcare and medical trainees and practitioners: so what's all the fuss about?' Critical and Reflective Practice in Education Volume 4 p.11-17

Jones S. \& Gelling L. (2013) Participation in Action Research. Nurse Researcher, $21(2)$,

Kateb G. (2011) Human Dignity The Bellnap Press of Harvard University Press, Cambridge

Khademi M., Mohammadi E. \& Vanaki Z. (2012) Nurses' experience of violations of their dignity Nursing Ethics, Vol. 19, 3: pp. 328-340. 
Kings Fund (2013) Leadership Survey, Kings Fund, London (see http://www.kingsfund.org.uk/publications/patient-centred-leadership)

Koukkanen L, Leino-Kilpi H \& Katajisto J. (2002). Do nurses feel empowered? Nurses' assessments of their own qualities and performance with regard to nurse empowerment. Journal of Professional Nursing; 18(6), 328-335

Latimer S., Chaboyer W. \& Gillespie B. (2014) Patient participation in pressure injury prevention: giving patient's a voice. Scandinavian Journal of Caring Sciences, 28(4), 648-656.

Lohne V., Høy B., Lillestø B. \& Sæeteren B. Tolo Heggestad A.K., Aasgaard T., Caspari S., Rehnsfeldt A., Råholm M-B., Slettebø A., Lindwall L \& Nåden D.(2016) Fostering dignity in the care of nursing home residents through slow caring Nursing Ethics, 0969733015627297, first published on February 4, 2016

Macklin R. (2003) Dignity is a useless concept. British Medical Journal; 327(7429), 1419-20.

Magee H., Parsons S. and Askham J. (2008) Measuring Dignity in Care for Older People: A research report for Help the Aged Picker Institute Europe

Matiti R.M. \& Baillie L. (Eds) (2011) Dignity in Healthcare: a practical approach for nurses and midwives Radcliffe Publishing Ltd, London

McLeod J. (2011). Qualitative Research in Counselling and Psychotherapy. London: SAGE

Naden D., Roholm M-B, Lohne V \& Eriksson K. (2013) Nursing Ethics and Dignity Nursing Ethics online special issue (http://nej.sagepub.com/site/Additional/dignity.pdf )

Nordenfelt L. (2009) Dignity in Care for Older People. Oxford: Blackwell Publishing Northern Ireland Human Rights Commission (2012). In Defence of Dignity: The human rights of older people in nursing homes. Belfast: Northern Ireland Human Rights Commission

Nursing and Midwifery Council (2015) The Code: professional standards of practice and behaviour for nurses and midwives. NMC: London

Pinker S. (2008). The stupidity of dignity. The New Republic, 28 May 2008 .

Accessed online:

http://pinker.wjh.harvard.edu/articles/media/The\%20Stupidity\%20of\%20Dignity.htm (accessed 05/07/15)

Rao A. (2012). The contemporary construction of nurse empowerment. Journal of Nursing Scholarship; 44(4), 396-402 
Ross T. (2013) 'Elderly who fear care home abuse' The Telegraph 12/11/2013 .

Accessed online: http://www.telegraph.co.uk/health/elderhealth/10445449/Elderlywho-fear-care-home-abuse.html (accessed 05/07/15)

Sabatino L., Kangasniemi M.K., Rocco G., Alvaor R. \& Stievano A. (2012) Nurses' perceptions of professional dignity in hospital settings Nursing Ethics,

0969733014564103, first published on December 30, 2014

Sama M \& Shoaf V. (2007). Ethical leadership for the professions. Journal of Business Ethics; 78, 39-46

Skills for Care (2012). The common core principles: Dignity. Accessed online: www.skillsforcare.org.uk/dignity (accessed on 05/07/15)

Stabell A, \& Naden D. (2006). Patients' dignity in a rehabilitation ward: ethical challenges for nursing staff. Nursing Ethics; 13(3), 236-48

Sturm B.A. \& Dellert J.C. (2015) Exploring nurses' personal dignity, global selfesteem and work satisfaction Nursing Ethics 0969733014567024, first published on February 9

Tranvåg O., Peterson K.A., \& Naden D. (2015) Relational interactions preserving dignity experience: Perceptions of persons living with dementia

Nursing Ethics, 22 (5) pp. 577-593

Willamson G R, Bellman L, Webster J. (2012). Action Research in Nursing and Healthcare London: SAGE

Wong C. \& Laschinger H. (2013) Authentic leadership. Performance and job satisfaction: the mediating role of empowerment. Journal of Advanced Nursing, 69(4), 947-59. 